CLINICAL STUDY

\title{
Course of placental $11 \beta$-hydroxysteroid dehydrogenase type 2 and 15-hydroxyprostaglandin dehydrogenase mRNA expression during human gestation
}

\author{
Ellen Schoof, Michaela Girstl, Wolfgang Frobenius ${ }^{1}$, Michael Kirschbaum ${ }^{2}$, Reinald Repp, Ina Knerr, \\ Wolfgang Rascher and Jörg Dötsch \\ Departments of Pediatrics, ${ }^{1}$ Obstetrics and Gynecology, University of Erlangen-Nuremberg and ${ }^{2}$ Department of Obstetrics and Gynecology, \\ University of Giessen, Germany \\ (Correspondence should be addressed to Jörg Dötsch, Klinik für Kinder und Jugendliche, Friedrich-Alexander-Universität Erlangen-Nürnberg, \\ Loschgestrasse 15, 91054 Erlangen, Germany; Email: JoergWDoetsch@yahoo.com)
}

\begin{abstract}

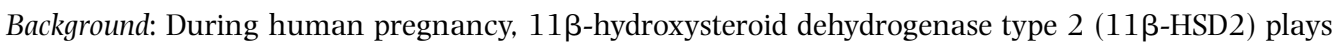
an important role in protecting the fetus from high maternal glucocorticoid concentrations by converting cortisol to inactive cortisone. Furthermore, 11ß-HSD2 is indirectly involved in the regulation of the prostaglandin inactivating enzyme 15-hydroxyprostaglandin dehydrogenase (PGDH), because cortisol reduces the gene expression and enzyme activity of PGDH in human placental cells.

Objective: To examine developmental changes in placental $11 \beta-H S D 2$ and PGDH gene expression during the 2 nd and 3rd trimesters of human pregnancies.

Methods: In placental tissue taken from 20 healthy women with normal pregnancy and 20 placentas of 17 mothers giving birth to premature babies, $11 \beta$-HSD2 and PGDH mRNA expression was determined using quantitative real-time PCR.

Results: Placental mRNA expression of $11 \beta-H S D 2$ and PGDH increased significantly with gestational age $(r=0.55, P=0.0002$ and $r=0.42, P=0.007)$. In addition, there was a significant correlation between the two enzymes $(r=0.58, P<0.0001)$.

Conclusions: In the course of pregnancy there is an increase in 11ß-HSD2 and PGDH mRNA expression in human placental tissue. This adaptation of $11 \beta-H S D 2$ prevents increasing maternal cortisol concentrations from transplacental passage and is exerted at the gene level. 11 $\beta$-HSD2 upregulation may also lead to an increase in PGDH mRNA concentrations that, until term, possibly delays myometrial contractions induced by prostaglandins.
\end{abstract}

European Journal of Endocrinology 145 187-192

\section{Introduction}

There are two isoforms of the enzyme 11ß-hydroxysteroid dehydrogenase (11 $\beta$-HSD), interconverting cortisol and cortisone. In the human fetoplacental unit, the type $1 \mathrm{NADP}^{+}$-dependent form is predominantly found in fetal membranes and acts primarily as an 11oxoreductase (formation of cortisol from cortisone) (1). Conversion of cortisol to cortisone is achieved by the type $2 \mathrm{NAD}^{+}$-dependent form (11ß-HSD2), which is the major form expressed in the syncytiotrophoblast of the placenta from the first trimester onward (1-4). Biochemical studies suggest that the two $11 \beta-\mathrm{HSD}$ enzymes contribute to the metabolism of maternal cortisol and the regulation of fetal cortisol and cortisone concentrations $(5,6)$. In the baboon, both enzymes have been shown to have important roles in regulating the timely activation of the fetal hypothalamic-pituitary-adrenocortical axis in addition to the maturation of the fetal adrenal gland (7).

During human pregnancy, maternal bound and free cortisol concentrations increase $(8-10)$. To protect the fetus from increased concentrations of maternal cortisol, enzyme activity of placental 11ß-HSD2 increases, forming a metabolic barrier. So far, a maturation of this enzyme activity during mid and late gestation has been shown in placental tissue of baboons, pigs and humans (11-13). In humans, placental tissue at term revealed greater $11 \beta-H S D 2$ enzyme activity than samples from 8-12 and 13-20 weeks (13). Another study with a small number of samples could not detect any difference in placental $11 \beta$-HSD2 immunoreactivity or mRNA expression measured by northern blot expression during gestation 
(14). However, no studies on $11 \beta$-HSD2 to quantify gene expression during pregnancy in humans have yet been performed.

In a dose-dependent manner, cortisol decreases 15hydroxyprostaglandin dehydrogenase (PGDH) activity and mRNA expression in placental and chorion trophoblast cells (15). The enzyme inactivates prostaglandin $\mathrm{E}_{2}\left(\mathrm{PGE}_{2}\right)$ and $\mathrm{PGF}_{2 \alpha}$ by formation of 15-ketoprostaglandins in placenta and chorion. It is localized primarily in chorionic trophoblasts, but also in the syncytiotrophoblast and the intermediate trophoblast of the placenta (16). For most of the duration of pregnancy, PGDH minimizes myometrial contractility, keeping prostaglandins synthesized by amnion or chorion from reaching decidua and myometrium (16). During early gestation, PGDH activity has been shown to increase (17).

PGDH activity and gene expression have been extensively studied at term and in premature deliveries. In chorion, but not in the placenta, of women going into spontaneous labour at term, levels of PGDH mRNA and activity have been shown to decrease (18). However, studies examining placental PGDH gene expression during human pregnancy are lacking.

The objective of our study was to measure and relate $11 \beta$-HSD2 and PGDH gene expression during mid and late gestation in human placenta, using quantitative real-time PCR.

\section{Materials and methods}

\section{Patients}

The tissue for the study was collected in collaboration with the Departments of Obstetrics and Gynecology at the Universities of Erlangen-Nuremberg and Giessen. Informed consent was obtained from the patients. We obtained the tissue from three different parts of the placenta after removal of amnionic membrane and maternal decidua immediately post partum by vaginal delivery or caesarean section. The tissue originated from 20 healthy women with normal pregnancies (age 21-36 years; 11 at weeks $36-39$ of gestation and nine at weeks 40-42 of gestation; 13 spontaneous vaginal deliveries, four primary, and three secondary caesarean sections) and from 20 placentas from 17 premature deliveries (mothers' age 15-41 years). In the premature group, nine pregnancies terminated between the 18th and 27th weeks of gestation (five spontaneous vaginal deliveries, two primary and two secondary caesarean sections) and 11 between the 30th and 34th weeks of gestation (three spontaneous vaginal deliveries, seven primary and one secondary caesarean section). Three placentas originated from a quadruplet pregnancy and two placentas from a triplet pregnancy (primary caesarean section, 32nd and 33rd weeks of gestation respectively). The study was approved by the
Table 1 Characteristics of patients from whom placental tissue was obtained. Values are shown as means \pm S.E.M.

\begin{tabular}{lcc}
\hline & Term group & Preterm group \\
\hline Maternal age (years) & $29.6 \pm 1.0$ & $29.6 \pm 1.5(\mathrm{NS})$ \\
Gestational age (weeks) & $39.0 \pm 0.4$ & $28.1 \pm 1.1^{\star \star \star}$ \\
Placental weight (g) & $594 \pm 30$ & $291 \pm 27^{\star \star \star}$ \\
Newborns' weight (g) & $3186 \pm 121$ & $938 \pm 149^{\star \star \star}$
\end{tabular}

${ }_{\star \star \star} P<0.0001$, significant difference from term group. NS, not significant.

ethics committee of the Medical Faculty. Table 1 shows the patients' characteristics.

\section{RNA extraction and reverse transcription}

Total RNA was extracted from the tissues using guanidine-thiocyanate acid phenol (RNAzol, WAK Chemie, Medical GmbH, Bad Homburg, Germany). In view of the fact that placenta has a heterogenous nature, RNA was extracted twice from two separate parts from 13 premature and 18 term placentas. RNA concentrations were determined spectrophotometrically. One microgram of RNA was reversely transcribed in a volume of $20 \mu \mathrm{l}$ at $39{ }^{\circ} \mathrm{C}$ for $60 \mathrm{~min}$ (chemicals from Boehringer Mannheim, Mannheim, Germany).

\section{TaqMan real-time PCR}

The method has been validated in our laboratory and successfully used for measurements of gene expression in placental tissue previously (19). This novel approach is based upon the $5^{\prime}$ exonuclease activity of the Taq polymerase. Briefly, within the amplicon defined by a gene-specific oligonucleotide primer pair, an oligonucleotide probe labelled with two fluorescent dyes is designed. As long as the probe is intact, the emission of a reporter dye (6-carboxy-fluorescein) at the $5^{\prime}$ end is quenched by the second fluorescence dye (6-carboxytetramethyl-rhodamine) at the $3^{\prime}$ end. During the extension phase of the PCR, the Taq polymerase cleaves the probe, releasing the reporter dye. An automated photometric detector combined with a special software (ABI Prism 7700 Sequence Detection System, PerkinElmer, Foster City, CA, USA) monitors the increasing reporter dye emission. The algorithm normalizes the signal to an internal reference $(\Delta \mathrm{Rn})$ and calculates the threshold cycle number $\left(C_{T}\right)$, when $\Delta$ Rn reaches 10 times the standard deviation of the baseline. The $C_{T}$ values of the probes are interpolated to an external reference curve constructed by plotting the relative or absolute amounts of a serial dilution of a known template against the corresponding $C_{T}$ values.

Commercial reagents (TaqMan PCR Reagent Kit, Perkin-Elmer, Weiterstadt, Germany) and conditions were in accordance with the manufacturer's procedure. To $25 \mu \mathrm{l}$ reaction mix were added $2.5 \mu \mathrm{l}$ cDNA (reverse transcription mixture) and oligonucleotides 
Table 2 Primers and TaqMan probes.

\begin{tabular}{|c|c|}
\hline GAPDH & \\
\hline Forward & 5'-CCCATGTTCGTCATGGGTGT-3' \\
\hline Reverse & 5'-TGGTCATGAGTCCTTCCACGATA- $3^{\prime}$ \\
\hline TaqMan probe & $5^{\prime}$ (FAM)-CTGCACCACCAACTGCTTAGCACCC-(TAMRA) $3^{\prime}$ \\
\hline$\beta$-actin & \\
\hline Forward & $5^{\prime}$-GCGAGAAGATGACCCAGGATC-3' \\
\hline Reverse & 5'-CCAGTGGTACGGCCAGAGG-3' \\
\hline TaqMan probe & $5^{\prime}$ (FAM)-CCAGCCATGTACGTTGCTATCCAGGC-(TAMRA) $3^{\prime}$ \\
\hline PBGD & \\
\hline Forward & 5'-TGTGCTGCACGATCCCG-3' \\
\hline Reverse & 5'-ACACTGCAGCCTCCTTCCAG-3' \\
\hline TaqMan probe & 5' (FAM)-CTTCGCTGCATCGCTGAAAGGGC-(TAMRA) 3' \\
\hline 11ß-HSD & \\
\hline Forward & 5'-CCGTATTGGAGTTGAACAGCC-3' \\
\hline Reverse & $5^{\prime}$-CAACTACTTCATTGTGGCCTGC-3' \\
\hline TaqMan probe & $5^{\prime}$ (FAM)-CTAGAGTTCACCAAGGCCCACACCACC-(TAMRA) $3^{\prime}$ \\
\hline PGDH & \\
\hline Forward & 5'-AAGCAAAATGGAGGTGAAGGC-3' \\
\hline Reverse & 5'-TGGCATTCAGTCTCACACCAC-3' \\
\hline TaqMan probe & $5^{\prime}$ (FAM)-CATCTTTAGCAGGACTCATGCCCGTTG-(TAMRA) $3^{\prime}$ \\
\hline
\end{tabular}

FAM, 6-carboxy-fluorescein; TAMRA, 6-carboxy-tetramethyl-rhodamine.

with a final concentration of $300 \mathrm{nmol} / \mathrm{l}$ primers and $200 \mathrm{nmol} / \mathrm{l}$ TaqMan hybridization probe. The oligonucleotides of each target of interest were designed using the Primer Express software (Perkin-Elmer), using uniform selection parameters that allowed the application of the same cycle conditions confirmed by primer optimization. All the primers and probes were purchased from Perkin-Elmer Applied Biosystems (Weiterstadt, Germany) and Eurogentec (Seraing, Belgium). The thermocycler parameters were $50{ }^{\circ} \mathrm{C}$ for $2 \mathrm{~min}$, $95{ }^{\circ} \mathrm{C}$ for $10 \mathrm{~min}$, followed by 40 cycles of $95{ }^{\circ} \mathrm{C}$ for $15 \mathrm{~s}$ and $60{ }^{\circ} \mathrm{C}$ for $1 \mathrm{~min}$. Serial dilutions of one of the samples served as reference, providing relative quantification of the unknown samples.

$11 \beta-H S D 2$ and $P G D H$ gene expression was related to the housekeeping genes glyceraldehyde-3-phosphate dehydrogenase (GAPDH), $\beta$-actin, and porphobilinogen deaminase $(P B G D)$. In former studies, $P B G D$ has proved suitable as housekeeping gene $(20,21)$; its sequence does not co-amplify pseudogenes. Table 2 shows the primers and TaqMan probes used.

\section{Statistical analysis}

All values are expressed as means \pm S.E.M. After being tested for Gaussian distribution, parametric data were compared using Student's $t$-test. Data of mRNA expression were interrelated and related to birth weight and placental weight using linear regression for parametric data. A $P$ value less than 0.05 was considered significant.

\section{Results}

With the passage of gestational age, a significant increase in placental 11 $\beta$-HSD2/PBGD mRNA expression $(r=0.55, P=0.0002$; Fig. 1a) could be observed.
Normalization of $11 \beta$-HSD2 to $\beta$-actin and GAPDH revealed similar results $(r=0.53, P=0.0004$ and $r=$ $0.56, P=0.0002$ respectively). 11ß-HSD2/PBGD gene expression was significantly greater in placental tissue obtained at term than from patients who delivered prematurely $(10.3 \pm 1.18$ relative units (RU) and $3.15 \pm 0.93 \mathrm{RU}, P<0.0001$ ) (Fig. 2a). Again, normalization to $\beta$-actin and GAPDH confirmed the results $(P=0.0002$ and $P=0.0001$ respectively). Significant correlations of placental 11 $\beta$-HSD2/PBGD mRNA expression were seen to birth weight $(r=0.57, P=$ $0.0004 ; 11 \beta$-HSD $2 / \beta$-actin: $r=0.59, \quad P=0.0002$; $11 \beta$-HSD2/GAPDH: $\quad r=0.63, \quad P<0.0001)$ and to placental weight $(r=0.57, P=0.0008 ; 11 \beta$-HSD2/ $\beta$-actin: $r=0.60, P=0.0004 ; 11 \beta$-HSD2/PBGD: $r=$ $0.62, P=0.0002)$.

As for $11 \beta-H S D 2$, there was an increase in gestational age-related PGDH/PBGD mRNA expression $(r=0.42, \quad P=0.007$; Fig. $1 b)$. Normalization of $P G D H$ to $\beta$-actin $(r=0.44, P=0.005)$ and GAPDH $(r=0.51, P=0.0009)$ showed similar results.

The gene expression of $P G D H / P B G D$ was significantly greater in placentas of patients giving birth to term babies than in those delivering premature neonates $(9.07 \pm 1.09 \mathrm{RU}$ and $4.63 \pm 0.83 \mathrm{RU}, P=$ $0.002)$ (Fig. 2b). Relation to $\beta$-actin and GAPDH also revealed significant results $(P=0.02$ and $P=0.01$ respectively). A significant correlation of placental PGDH/PBGD mRNA expression to birth weight was found $(r=0.38, P=0.03 ; \mathrm{PGDH} / \beta$-actin: $r=0.35$, $P=0.04 ;$ PGDH/GAPDH: $r=0.43, P=0.01$ ). However, there was no significant correlation between placental weight and $P G D H$ gene expression $(P>0.05)$ for all the housekeeping genes.

Finally, a significant correlation was found in respect to the gene expressions of the two enzymes $11 \beta-H S D 2 /$ $P B G D$ and $P G D H / P B G D(r=0.58, P<0.0001$, Fig. 

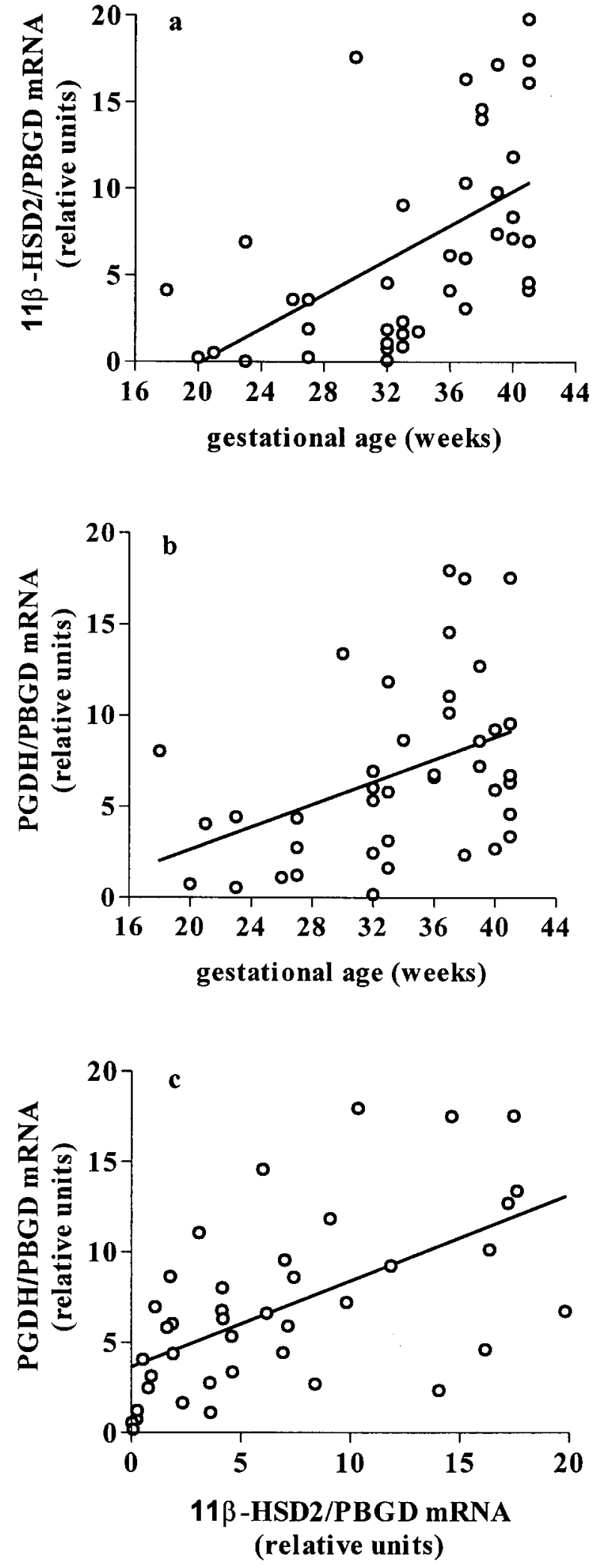
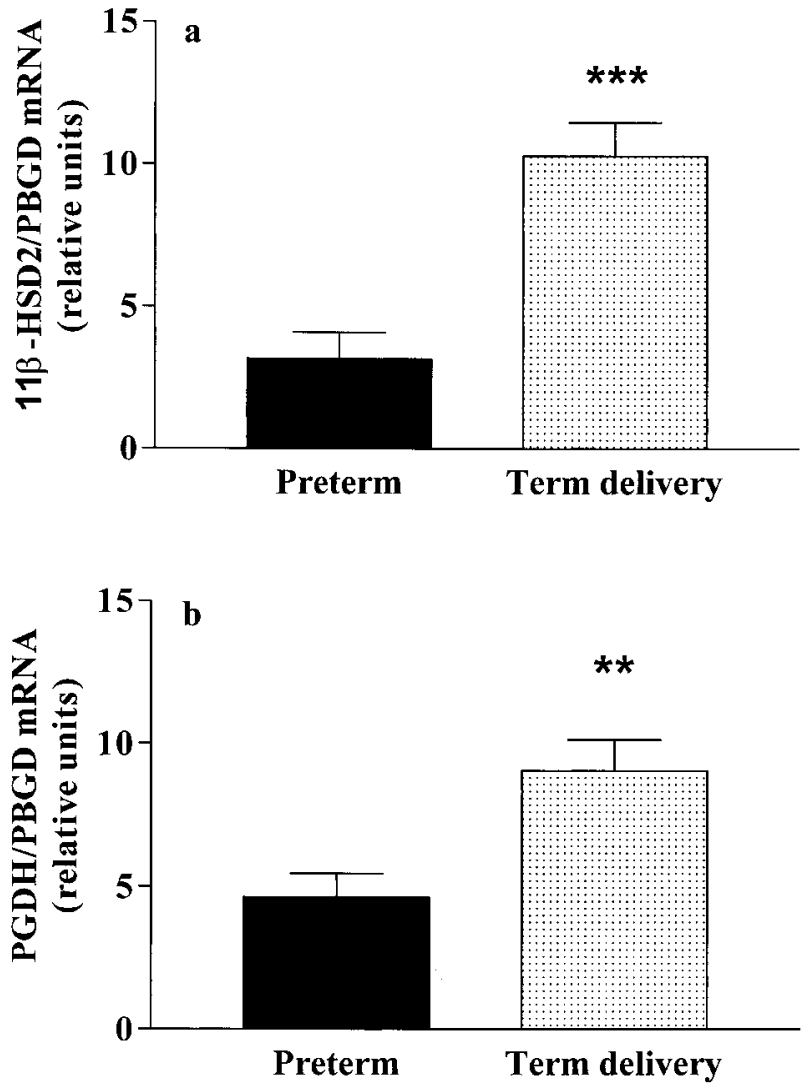

Figure 2 Significant increase in (a) $11 \beta$-HSD2/PBGD $(P<0.0001)$ and (b) $\mathrm{PGDH} / \mathrm{PBGD}(P=0.002)$ mRNA expression in placental tissue from term deliveries compared with premature deliveries (Preterm).

1c). Similar results were achieved when normalizing to the housekeeping genes $\beta$-actin $(r=0.33, P=0.03)$ and GAPDH $(r=0.36, P=0.02)$.

The mode of birth - spontaneous vaginal delivery or caesarean section - did not influence either $11 \beta$-HSD2 or PGDH gene expression $(P>0.05)$ in the placental tissues.

To confirm the results, RNA was extracted from a different part in 31 placentas and the genes $11 \beta$-HSD2, $P G D H$ and $P B G D$ were quantified twice. Again, a correlation to gestational age was found $(11 \beta-H S D 2 /$ PBGD: $r=0.47, P=0.0007$; PGDH/PBGD: $r=0.43$, $P=0.01$ ). Gene expression in term placentas was confirmed to be significantly greater than in premature placentas (11 $\beta-H S D 2 / P B G D: \quad P=0.0004$; $P G D H / P B G D: P=0.02)$ in addition to the correlation between 11ß-HSD2 and PGDH mRNA expression

Figure 1 Significant increase in (a) $11 \beta$-HSD2/PBGD $(r=0.55$, $P=0.0002)$ and (b) PGDH/PBGD $(r=0.42, P=0.0007) \mathrm{mRNA}$ expression in placental tissue with advancing gestation. (c) Correlation between the gene expression of $11 \beta-H S D 2 / P B G D$ and $P G D H / P B G D$ in placentas of premature and term deliveries $(r=0.58, P<0.0001)$.

www.eje.org 
$(r=0.44, P=0.01)$. The relation to birth weight, however, could only be demonstrated for 11 $\beta$-HSD2/ PBGD $(r=0.67, P=0.0003)$.

\section{Discussion}

In the course of pregnancy there is a significant increase in the gene expression of the cortisol and prostaglandin metabolizing enzymes $11 \beta-H S D 2$ and PGDH in human placental tissue. As far as we know, this was demonstrated for the first time in the present study. Our results are supported by some theories and findings of other investigators. We were able to provide evidence that the previously described increase in placental $11 \beta$-HSD2 enzyme activity during human pregnancy is based on increased gene expression (13).

According to former in vitro work, $11 \beta-H S D 2$ is regulated by oestrogens in a paracrine manner (22). In the placenta, oestrogens are synthesized predominantly from androgen precursors produced by the fetal adrenal. Therefore, increasing quantities of these androgens cause placental oestrogen concentrations to increase in the course of pregnancy. Consecutively, this seems to up-regulate $11 \beta$-HSD2 gene expression. This interrelation is further strengthened by our finding that $11 \beta-H S D 2$ gene expression correlates significantly with birth weight and placental weight. The mode of delivery had no influence on placental $11 \beta$ HSD2 mRNA expression. These data are in line with a previous study showing unchanged $11 \beta$ HSD2 mRNA levels in chorion and placenta as measured by northern blot after different modes of labour (1).

As mentioned, studies in baboons have led to the hypothesis that increasing $11 \beta-H S D 2$ enzyme activity is not only protecting the fetus from high maternal cortisol concentrations, but also supporting the maturation of the fetal adrenal (7). When pregnancy progresses, $11 \beta$-HSD2 builds a transplacental barrier, preventing cortisol from reaching the fetus. The resulting lower serum cortisol concentrations are believed to stimulate the activation of the fetal hypothalamo-pituitary-adrenocortical axis. As a consequence, the definitive zone of the adrenal grows to achieve adequate adrenocortical function. Our results support the notion that the regulation of $11 \beta-H S D 2$ and fetal adrenal development is taking place in humans in a similar way as in primates.

Glucocorticoids inhibit PGDH enzyme activity in cultured human placental syncytiotrophoblast and chorion trophoblast cells (15). PGDH mRNA expression is increased by progesterone (23). The inhibitory effect of cortisol on PGDH activity seems to be mediated by the mineralocorticoid receptor, as has been demonstrated recently $(15,24)$. We found a positive correlation between $11 \beta$-HSD2 and PGDH mRNA expression. In our opinion, this supports the hypothesis that increased oxidation of cortisol to inactive cortisone allows PGDH activity to increase with advancing gestation. Increasing PGDH activity provides an increasing capacity for prostaglandin metabolism to decrease myometrial contractility until term (25).

During the first 7-17 weeks of gestation, an increase in PGDH activity could be demonstrated as a function of gestational age (17). Per unit of weight, the authors found less PGDH activity in placental homogenates at 17 weeks than in term placentas.

At term, progesterone is displaced from glucocorticoid receptors by increased concentrations of cortisol, leading to a reduced mRNA expression of PGDH. This enables prostaglandins to reach the myometrium, increasing its contractility $(18,23)$. With respect to the chorion, previous investigators have shown a reduction of PGDH gene expression and activity more often in patients with spontaneous labour than in patients who underwent caesarean section $(16,18)$. As far as the placenta is concerned, our study has detected no difference in placental PGDH mRNA expression, regardless of the mode of delivery.

The increasing placental expression of the two important cortisol and prostaglandin metabolizing enzymes, 11ß-HSD2 and PGDH, during human gestation can be expected to generate low levels of active glucocorticoids and prostaglandins at the maternalfetal interface, promoting fetal maturation and uterine quiescence in late gestation. However, as labour is associated with increased concentrations of cortisol in maternal and fetal serum and amniotic fluid, this suggests that parturition is associated with enhanced cortisol and prostaglandin action at the uterineplacental interface. Furthermore, a positive correlation suggests an interaction of both enzymes.

\section{Acknowledgements}

We thank Ulla Jacobs and Ida Allabauer for their helpful assistance.

\section{References}

1 Sun K, Yang K \& Challis JR. Differential expression of 11 betahydroxysteroid dehydrogenase types 1 and 2 in human placenta and fetal membranes. Journal of Clinical Endocrinology and Metabolism 199782 300-305.

2 Krozowski Z, Maguire JA, Stein OA, Dowling J, Smith RE \& Andrews RK. Immunohistochemical localization of the 11 betahydroxysteroid dehydrogenase type II enzyme in human kidney and placenta. Journal of Clinical Endocrinology and Metabolism $1995802203-2209$.

3 Pepe GJ, Burch MG \& Albrecht ED. Expression of the 11 betahydroxysteroid dehydrogenase types 1 and 2 proteins in human and baboon placental syncytiotrophoblast. Placenta $1999 \mathbf{2 0}$ 575-582.

4 Arcuri F, Sestini S, Paulesu L, Bracci L, Carducci A, Manzoni F et al. 11Beta-hydroxysteroid dehydrogenase expression in first trimester human trophoblasts. Molecular Cellular Endocrinology 1998141 13-20.

5 Yang K. Placental 11 beta-hydroxysteroid dehydrogenase: barrier to maternal glucocorticoids. Reviews of Reproduction 19972 129-132. 
6 Klemcke HG. Dehydrogenase and oxoreductase activities of porcine placental 11 beta-hydroxysteroid dehydrogenase. Life Science 200066 1045-1052.

7 Pepe GJ \& Albrecht ED. Regulation of the primate fetal adrenal cortex. Endocrine Reviews 199011 151-176.

8 Dörr HG, Heller A, Versmold HT, Sippell WG, Herrmann M, Bidlingmaier $\mathrm{F}$ et al. Longitudinal study of progestins, mineralocorticoids, and glucocorticoids throughout human pregnancy. Journal of Clinical Endocrinology and Metabolism 198968 863868.

9 Challis JR, Matthews SG, Gibb W \& Lye SJ. Endocrine and paracrine regulation of birth at term and preterm. Endocrine Reviews 200021 514-550.

10 Petraglia F, Florio P, Nappi C \& Genazzani AR. Peptide signaling in human placenta and membranes; autocrine, paracrine, and endocrine mechanisms. Endocrine Reviews 199617 156-186.

11 Pepe GJ, Babischkin JS, Burch MG, Leavitt MG \& Albrecht ED. Developmental increase in expression of the messenger ribonucleic acid and protein levels of 11beta-hydroxysteroid dehydrogenase types 1 and 2 in the baboon placenta. Endocrinology $19961375678-5684$.

12 Klemcke HG \& Christenson RK. Porcine placental 11 betahydroxysteroid dehydrogenase activity. Biology of Reproduction $199655217-223$.

13 Shams M, Kilby MD, Somerset DA, Howie AJ, Gupta A, Wood PJ et al. 11Beta-hydroxysteroid dehydrogenase type 2 in human pregnancy and reduced expression in intrauterine growth restriction. Human Reproduction 199813 799-804.

14 Hirasawa G, Sasano H, Suzuki T, Takeyama J, Muramatu Y, Fukushima K et al. 11Beta-hydroxysteroid dehydrogenase type 2 and mineralocorticoid receptor in human fetal development. Journal of Clinical Endocrinology and Metabolism 199984 14531458.

15 Patel FA, Sun K \& Challis JR. Local modulation by 11 betahydroxysteroid dehydrogenase of glucocorticoid effects on the activity of 15-hydroxyprostaglandin dehydrogenase in human chorion and placental trophoblast cells. Journal of Clinical Endocrinology and Metabolism 199984 395-400.

16 Sangha RK, Walton JC, Ensor CM, Tai HH \& Challis JR. Immunohistochemical localization, messenger ribonucleic acid abundance, and activity of 15-hydroxyprostaglandin dehydrogenase in placenta and fetal membranes during term and preterm labor. Journal of Clinical Endocrinology and Metabolism 199478 982-989.

17 Keirse MJ, Erwich JJ \& Klok G. Increase in placental 15-hydroxyprostaglandin dehydrogenase in the first half of human pregnancy. Prostaglandins 198530 131-140.

18 Van Meir CA, Matthews SG, Keirse MJ, Ramirez MM, Bocking A \& Challis JR. 15-Hydroxyprostaglandin dehydrogenase: implications in preterm labor with and without ascending infection. Journal of Clinical Endocrinology and Metabolism 199782 969976.

19 Dötsch J, Nüsken KD, Knerr I, Kirschbaum M, Repp R \& Rascher W. Leptin and neuropeptide Y gene expression in human placenta: ontogeny and evidence for similarities to hypothalamic regulation. Journal of Clinical Endocrinology and Metabolism 1999 $842755-2758$

20 Fink L, Stahl U, Ermert L, Kummer W, Seeger W \& Bohle RM. Rat porphobilinogen deaminase gene: a pseudogene-free internal standard for laser-assisted cell-picking. BioTechniques 199926 510-516.

21 Cassinat B, Zassadowski F, Balitrand N, Barbey C, Rain JD, Fenaux $\mathrm{P}$ et al. Quantitation of minimal residual disease in acute promyelocytic leukemia patients with $\mathrm{t}(15 ; 17)$ translocation using real-time RT-PCR. Leukemia 200014 324-328.

22 Baggia S, Albrecht ED \& Pepe GJ. Regulation of 11 betahydroxysteroid dehydrogenase activity in the baboon placenta by estrogen. Endocrinology 1990126 2742-2748.

23 Patel FA, Clifton VL, Chwalisz K \& Challis JR. Steroid regulation of prostaglandin dehydrogenase activity and expression in human term placenta and chorio-decidua in relation to labor. Journal of Clinical Endocrinology and Metabolism 199984 291-299.

24 Funder JW. 15-Hydroxyprostaglandin dehydrogenase: Cinderella meets Prince Serendip. Journal of Clinical Endocrinology and Metabolism 199984 393-394.

25 Challis JR, Patel FA \& Pomini F. Prostaglandin dehydrogenase and the initiation of labor. Journal of Perinatal Medicine 199927 26-34.

Received 19 December 2000

Accepted 26 April 2001 